Check for updates

Cite this: RSC Adv., 2018, 8, 30310

\title{
A solution-processed tin dioxide film applicable as a transparent and flexible humidity sensor
}

\author{
Hwai-En Lin, (D) ${ }^{\text {a }}$ Yuta Katayanagi, ${ }^{\text {b }}$ Tetsuo Kishi, ${ }^{a}$ Tetsuji Yano ${ }^{a}$ \\ and Nobuhiro Matsushita*a
}

An all-solution-processed transparent tin oxide $\left(\mathrm{SnO}_{2}\right)$-based humidity sensor was directly prepared on borosilicate glass $\left(\mathrm{SnO}_{2}-\mathrm{G}\right)$ and a flexible polyethylene terephthalate $\left(\mathrm{SnO}_{2}-\mathrm{PET}\right)$ substrate without using a template. The entire process included film deposition by a spin-spray process at $90{ }^{\circ} \mathrm{C}$ and subsequent hot water treatment (HWT) at $100{ }^{\circ} \mathrm{C}$. The resistivity of the films dramatically decreased and had semiconductor characteristics after the HWT, even though the as-prepared $\mathrm{SnO}_{2}-\mathrm{G}$ and $\mathrm{SnO}_{2}-\mathrm{PET}$ samples were insulators. Based on the results, the variation of the resistivity could be attributed to the formation of a hydroxyl layer on the crystallized $\mathrm{SnO}_{2}$ surface. With the help of the HWT on the $\mathrm{SnO}_{2}$ films, the formation of tin hydroxyl derivatives provided mobile protons, which led to the variation of the electrical properties of $\mathrm{SnO}_{2}$ at ambient conditions with different humidities. The sensitivity of the $\mathrm{SnO}_{2}-\mathrm{G}$ $\mathrm{HWT}$ and $\mathrm{SnO}_{2}-\mathrm{PET}-\mathrm{HWT}$ at 95\% relative humidity $(\mathrm{RH})$ was 35.2 and 3.5 times higher, respectively, than that at $5 \% \mathrm{RH}$. Both the sensitivity of the $\mathrm{SnO}_{2}-\mathrm{G}-\mathrm{HWT}$ and $\mathrm{SnO}_{2}-\mathrm{PET}-\mathrm{HWT}$ samples showed a good uptrend corresponding to the increase of $\mathrm{RH}$ at $20 \pm 1{ }^{\circ} \mathrm{C}$, and the response/recovery time of $\mathrm{SnO}_{2}-\mathrm{G}$ $\mathrm{HWT}$ and $\mathrm{SnO}_{2}-\mathrm{PET}-\mathrm{HWT}$ was $51 / 38 \mathrm{~s}$ and $69 / 47 \mathrm{~s}$ in the $\% \mathrm{RH}$ range of $30-70 \%$ at $20 \pm 1{ }^{\circ} \mathrm{C}$, respectively.

Received 22nd May 2018 Accepted 18th August 2018

DOI: $10.1039 / \mathrm{c} 8 \mathrm{ra0} 4355 \mathrm{~h}$

rsc.li/rsc-advances to directly prepare a $\mathrm{SnO}_{2}$ film on a flexible substrate. ${ }^{9}$ A simple method for synthesizing $\mathrm{SnO}_{2}$ films was provided by Vayssieres and Graetzel in 2004. A film consisting of a homogeneous dispersion of crystalline $\mathrm{SnO}_{2}$ nanorods was successfully fabricated at $95{ }^{\circ} \mathrm{C}$ by conducting a low temperature hydrothermal process for 2 days. ${ }^{10}$ Thereafter, Her et al. investigated the material properties and luminescence phenomenon of $\mathrm{SnO}_{2}$ films with respect to the process conditions. ${ }^{11}$ However, the process still took one day for the deposition of the film only $100 \mathrm{~nm}$ in thickness. To the best of our knowledge, these are the only two examples of the successful fabrication of $\mathrm{SnO}_{2}$ film on non-seeded substrates below $100{ }^{\circ} \mathrm{C}$ without post heat treatment $\left(>100{ }^{\circ} \mathrm{C}\right)$. Therefore, further research is required for the development of a low-temperature process for the fabrication of $\mathrm{SnO}_{2}$ films, and it is also strongly required to understand the relationship between the process conditions and the film properties.

Herein, we present a two-step but more efficient method for the synthesis of a $\mathrm{SnO}_{2}$ film on a non-seeded substrate at a temperature below $100{ }^{\circ} \mathrm{C}$. First, the $\mathrm{SnO}_{2}$ films were deposited by a spin-spray process, as shown in Fig. 1 . The spinspray technique has been applied for the preparation of ferrite films for noise suppressors. ${ }^{12}$ The spin-spray process could supply a continuous fresh solution to avoid the inconstant concentration of the precursor solution. In addition, because the formation of free nuclei would be removed from the spinning disk, the nuclei could selectively grow on the substrate. These effects of the spin-spray technique led to
${ }^{a}$ Department of Materials Science and Engineering, School of Materials and Chemica Technology, Tokyo Institute of Technology, 2-12-1 Ookayama, Meguro-ku, Tokyo 152-8550, Japan. E-mail: matsushita.n.ab@m.titech.ac.jp

${ }^{b}$ Department of Technology Education, Faculty of Education, Gunma University, 4-2 Aramaki-machi, Maebashi, Gunma 371-8510, Japan 


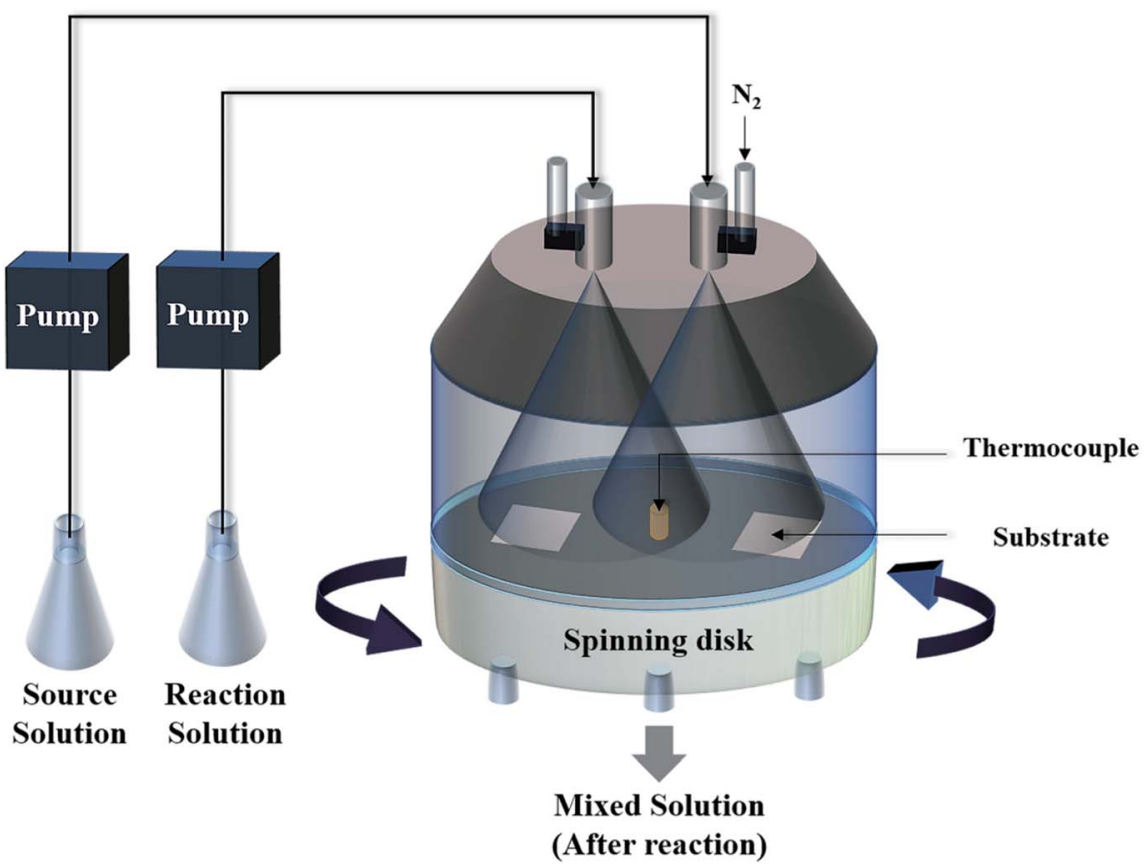

Fig. 1 A schematic diagram of the spin-spray apparatus.

a relatively higher deposition rate and crystal quality of the deposited films. Similarly, a high-speed fabrication of crystallized $\mathrm{ZnO}$ film was successfully accomplished by a spinspray method in $2010 .{ }^{13}$ It should be noted that the spinspray process possesses relatively approachable process conditions including low operating temperature $\left(\leq 100{ }^{\circ} \mathrm{C}\right)$ and the ability of working at atmospheric pressure. The vacuum systems and the relatively high-power supply machines are not required in spin-spray process. Compared with the sputtering, thermal evaporation and chemical vapor deposition process which are often used to prepare the $\mathrm{SnO}_{2}$ films, the spin-spray process could be regarded as a relative low-cost synthesis method. Therefore, the spin-spray process has a great potential for application to other kinds of material. After the preparation of the $\mathrm{SnO}_{2}$ films, the samples were placed in an oven for hot water treatment (HWT) at $100{ }^{\circ} \mathrm{C}$. HWT is a simple low temperature $\left(\leq 100^{\circ} \mathrm{C}\right)$ solution process that can be used to rapidly fabricate a crystallized oxide layer on a metal surface in pure boiling water. Lamberti et al. first demonstrated that crystallized $\mathrm{TiO}_{2}$ nanotubes could be prepared on a titanium surface by a HWT process. ${ }^{14}$ Afterward, a systematic investigation of HWT of several kinds of metal was performed by Saadi et al., which showed that HWT could effectively trigger the oxidation reaction, crystallization, and morphological architecture of numerous elements..$^{15}$ Because most of the research has focused on the effect of HWT for the formation of crystallized oxides on a metal surface, there has been limited investigations of the effect of HWT on metal oxides. Nose et al. demonstrated the reaction of the oxidation state transformation from crystallized $\mathrm{SnO}$ to amorphous $\mathrm{SnO}_{2}$ by using HWT. ${ }^{16}$ However, the crystallization and phase transformation reaction of $\mathrm{SnO}_{2}$ were strongly influenced by the process conditions; therefore, the reported methods might not always be suitable for films prepared by different processes. Therefore, it is worth performing further research to classify the reaction mechanism of solution-processed $\mathrm{SnO}_{2}$ films at a relatively low temperature. Inspired by the reasons mentioned above, we first demonstrated a novel two-step method including film deposition at $90{ }^{\circ} \mathrm{C}$ and a post HWT process at $100{ }^{\circ} \mathrm{C}$ for the fabrication of a transparent $\mathrm{SnO}_{2}$ film on both glass and flexible PET substrates. The material properties and the humidity sensing properties of $\mathrm{SnO}_{2}$ films were investigated, and the effect of the HWT process on the $\mathrm{SnO}_{2}$ based humidity sensor are discussed in this study.

\section{Materials and methods}

\section{1 $\mathrm{SnO}_{2}$ film fabrication and HWT process}

$\mathrm{SnO}_{2}$ films were deposited on borosilicate glass and flexible PET substrates. Before deposition, the substrates were sonicated in deionized water, ethanol, acetone, and deionized water for $5 \mathrm{~min}$ to remove impurities on the substrate surface. Afterward, the substrates were placed into a UV-Ozone cleaner (BIOFORCE nanosciences, UV Ozone Cleaner ProCleaner ${ }^{\mathrm{TM}}$ Plus) for further $30 \mathrm{~min}$. The $\mathrm{SnO}_{2}$ films were deposited by a spin-spray process using stannous fluoride $\left(\mathrm{SnF}_{2}, 97 \%\right.$, Morita Chemical Industries co., Ltd.) and sodium nitrate $\left(\mathrm{NaNO}_{3}, 99.0 \%\right.$, Wako Pure Chemical Industries, Ltd.). These precursor materials were dissolved in $1.0 \mathrm{~L}$ deionized water. They were used as a Sn ion source solution and reaction solution, respectively. The chemical reactions between the source solution and the reaction solution are showing below.

$3 \mathrm{Sn}(\mathrm{OH})_{2}+2 \mathrm{NaNO}_{3}+2 \mathrm{H}^{+} \rightarrow 3 \mathrm{SnO}_{2}+2 \mathrm{NO}+2 \mathrm{Na}^{+}+4 \mathrm{H}_{2} \mathrm{O}(1)$ 
$\mathrm{Sn}(\mathrm{OH})_{2}+2 \mathrm{NaNO}_{3}+2 \mathrm{H}^{+} \rightarrow \mathrm{SnO}_{2}+2 \mathrm{NO}_{2}+2 \mathrm{Na}^{+}+2 \mathrm{H}_{2} \mathrm{O}(2)$

During spin-spray, the sample stage was heated to $90{ }^{\circ} \mathrm{C}$ and kept rotating at $120 \mathrm{rpm}$. The spray solution $\left(\mathrm{SnF}_{2}\right.$ and $\mathrm{NaNO}_{3}$ solution) was mixed together at a molar ratio of $1: 1$. All the chemical compounds were employed in the deposition without further refinement. After the deposition, the $\mathrm{SnO}_{2}$ film samples were thoroughly washed by deionized water to remove any contaminants on the sample surface.

Samples with and without the post HWT process were prepared for comparison. The HWT method was carried out by placing the $\mathrm{SnO}_{2}-\mathrm{G}$ and $\mathrm{SnO}_{2}-\mathrm{PET}$ samples into a glass beaker containing

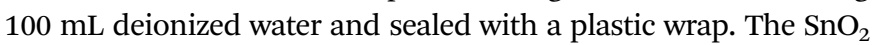
samples were heated in deionized water by a regular laboratory oven at $100{ }^{\circ} \mathrm{C}$ for $12 \mathrm{~h}$ and cooled down to room temperature (20 $\left.{ }^{\circ} \mathrm{C}\right)$ naturally. Afterward, all the samples were dried in an oven at $60^{\circ} \mathrm{C}$ for $1 \mathrm{~h}$. As a control group, the samples that did not undergo the post HWT process were directly placed in the oven and dried at $60^{\circ} \mathrm{C}$ for $1 \mathrm{~h}$. The reason why the drying process was applied is to remove the remained water molecular on $\mathrm{SnO}_{2}$ sample surface which formed during HWT process. The research results have revealed that the drying process at $60^{\circ} \mathrm{C}$ for $1 \mathrm{~h}$ would not damage the $\mathrm{Sn}-\mathrm{OH}$ derivatives formed on $\mathrm{SnO}_{2}$ surface, and the $\mathrm{SnO}_{2}$ layer humidity sensor could still work effectively after conducting this approach. Besides, to rule out the possibility that the substrate might reveal the humidity sensing behaviour. The HWT process was also applied on untreated borosilicate glass and PET substrate. The results revealed that both the borosilicate glass and PET substrate did not show any conductive or semiconductor conductive characteristics while examining by LCR meter at $20 \pm$ $1{ }^{\circ} \mathrm{C}$ before or after HWT. Therefore, we believed that the influence of both borosilicate glass and PET substrate during sensitivity measurement could be neglected.

\subsection{Characterization}

The surface morphology and cross-section of $\mathrm{SnO}_{2}$ were observed by field emission scanning electron microscopy (FE-
SEM, HITACHI, S-4700) in secondary electron mode with a working voltage $8 \mathrm{kV}$. The crystallinity and microstructure were analyzed by an X-ray diffractometer (XRD, BRUKER co., D8 FOCUS/TXS) at a scan angle (2 $\theta)$ range of 20 to $80^{\circ}$. The X-ray was generated by a $\mathrm{Cu}-\mathrm{K} \alpha$ target operated at $35 \mathrm{kV}$ and 300 $\mathrm{mA}$ with a wavelength of $0.15418 \mathrm{~nm}$. The chemical state of the $\mathrm{SnO}_{2}$ films was examined by X-ray photoelectron spectroscopy (XPS, Physical Electronics, Inc., PHI 5000). Fourier-transfer infrared spectroscopy (FTIR, SHIMADZU co., IRPrestige-21) was carried out by mixing the peeled $\mathrm{SnO}_{2}$ powder $(1 \mathrm{mg})$ with potassium bromide $(\mathrm{KBr}, 300 \mathrm{mg})$ to evaluate the variation in the chemical composition of the $\mathrm{SnO}_{2}$ film before and after HWT for comparison. In addition, the transparency and absorbance of $\mathrm{SnO}_{2}$ in the ultraviolet-visible (UV-vis) region were evaluated by a V-570 spectrophotometer (JASCO).

\subsection{Measurement of the humidity sensing}

The resistivity measurements of $\mathrm{SnO}_{2}$-based sensor corresponding to different $\mathrm{RH}$ were carried out at $20 \pm 1^{\circ} \mathrm{C}$ in a sealed threeneck flask. The $\mathrm{RH}$ values were controlled by using saturated salt solutions of $\mathrm{CH}_{3} \mathrm{COOK}, \mathrm{K}_{2} \mathrm{CO}_{3}, \mathrm{NaBr}, \mathrm{NaCl}$, and $\mathrm{K}_{2} \mathrm{NO}_{3}$, which yielded humidity levels of $23 \%, 43 \%, 59 \%, 75 \%$, and $95 \%$, respectively. ${ }^{17,18}$ All the saturated solutions were kept overnight in the flask to ensure the humidity environment reached an equilibrium before measurement. A dried atmosphere was obtained by placing solid $\mathrm{NaOH}(5 \% \mathrm{RH})$ in a closed flask. ${ }^{19,20} \mathrm{~A}$ standard hydrometer was employed for confirming the precision of the relative humidity. The electrical resistance of the sensing material was measured by a basic 2 probe LCR meter (inductance $(L)$, capacitance $(C)$, and resistance $(R))$ in DC resistance mode under different humidity conditions, and the distance between the two measurement points was maintained at $10 \mathrm{~mm}$. The sensitivity of the $\mathrm{SnO}_{2}-\mathrm{G}$ and $\mathrm{SnO}_{2}$-PET were defined as $S=\left(R_{0}-R\right) / R_{0}$, in which $R_{0}$ is the resistance of $\mathrm{SnO}_{2}$ at $5 \% \mathrm{RH}$. In addition, the examination of humidity response and recovery time were carried out by using the 2 probe LCR meter to measure the resistance change of both the $\mathrm{SnO}_{2}-\mathrm{G}$ and $\mathrm{SnO}_{2}$-PET samples during the

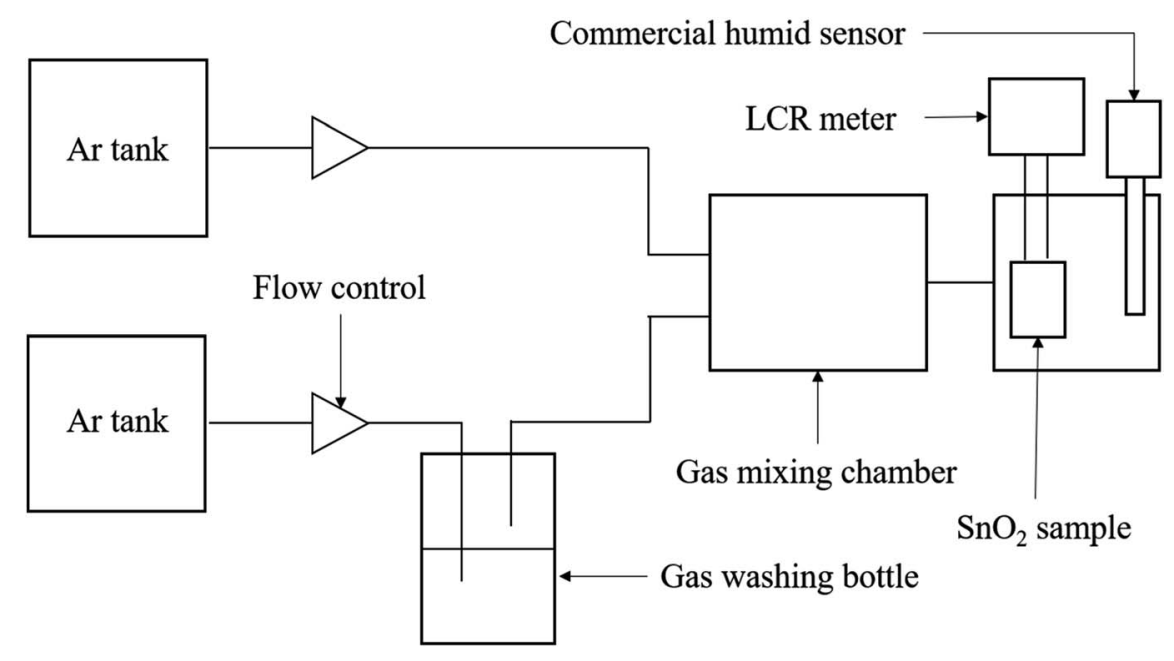

Fig. 2 The scheme of the sensing property measurement system. 
humidification from 30 to $70 \% \mathrm{RH}$ as well as the desiccation from 70 to $30 \% \mathrm{RH}$ at $20 \pm 1{ }^{\circ} \mathrm{C}$. The scheme of sensing property measurement system was illustrated in Fig. 2. The RH\% value was controlled by mixing the dry and humidified argon gas flow, and the flow rate was kept at $100 \mathrm{sccm}$.

\section{Results and discussions}

\subsection{The optical properties of $\mathrm{SnO}_{2}-\mathrm{G}$ and $\mathrm{SnO}_{2}-\mathrm{PET}$}

The transmittance and absorbance spectrum of $\mathrm{SnO}_{2}$ before and after HWT were examined by a UV-vis spectrometer and shown in Fig. 3. According to Fig. 3(A), the $\mathrm{SnO}_{2}-\mathrm{G}$ film had a higher transmittance than $\mathrm{SnO}_{2}$-PET owing to the difference in the pristine transparency of the glass and PET substrates. The pristine transparency of borosilicate glass and the PET substrate were $90 \%$ and $70 \%$, respectively, within the visible light wavelength range. Both $\mathrm{SnO}_{2}-\mathrm{G}$ and $\mathrm{SnO}_{2}-\mathrm{PET}$ showed a slight decrease in transparency after undergoing the HWT process. The reasonable explanations for this phenomenon were the formation of defects inside the $\mathrm{SnO}_{2}$ layer on the
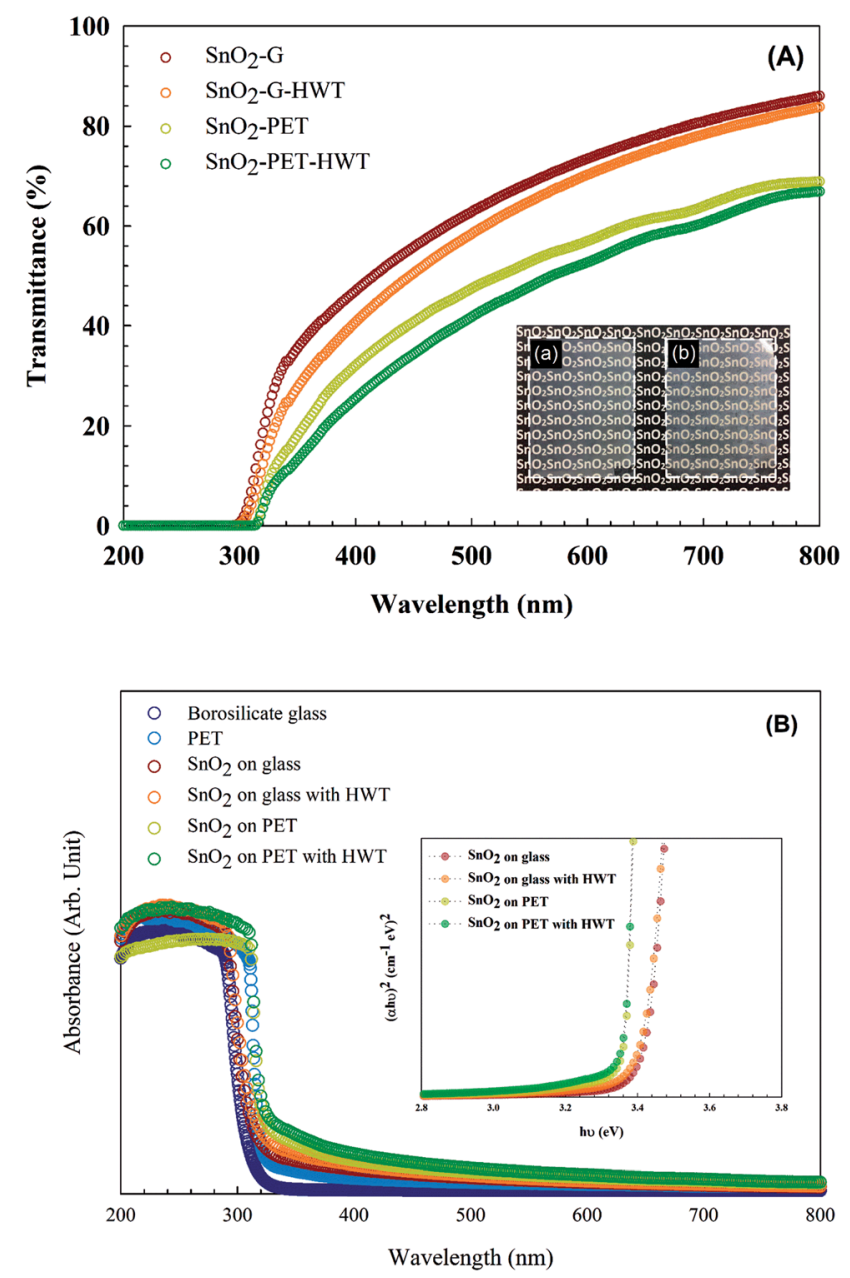

Fig. 3 The optical properties of the $\mathrm{SnO}_{2}$ samples. (A) The transmittance results for $\mathrm{SnO}_{2}$. The inset photographs show (a) $\mathrm{SnO}_{2}-\mathrm{G}$ and (b) $\mathrm{SnO}_{2}-$ PET samples after the HWT process. (B) The absorbance and band-gap spectra. surface layer during the HWT process. The formation of these defects would cause the scattering of light and lead to a decrease in transparency. The insets (a) and (b) in Fig. 3(A) are photos of $\mathrm{SnO}_{2}-\mathrm{G}$ and $\mathrm{SnO}_{2}-\mathrm{PET}$ samples that underwent HWT for $12 \mathrm{~h}$, which show the semitransparent characteristics. As shown in Fig. 3(B), the energy band gap of $\mathrm{SnO}_{2}-\mathrm{G}$ and $\mathrm{SnO}_{2}-$ PET were 3.40 and $3.35 \mathrm{eV}$, respectively, which were slightly lower than the typical band gap of $\mathrm{SnO}_{2}$ at $3.50 \mathrm{eV}$. In addition, there was no obvious change of energy band gap of the samples before and after the HWT process.

\subsection{Elemental analysis of $\mathrm{SnO}_{2}-\mathrm{G}$ and $\mathrm{SnO}_{2}-\mathrm{PET}$}

To clarify the effects of the HWT process on the $\mathrm{SnO}_{2}$ film, FTIR studies were carried out to compare the variation of the chemical composition before and after HWT. As shown in Fig. 4(A), both the $\mathrm{SnO}_{2}-\mathrm{G}$ and $\mathrm{SnO}_{2}-\mathrm{G}-\mathrm{HWT}$ samples revealed a peak located at $1638 \mathrm{~cm}^{-1}$ and a broad band at approximately 2500$3600 \mathrm{~cm}^{-1}$, which corresponded to the bending mode of the $\mathrm{H}-\mathrm{O}-\mathrm{H}$ bond groups of the adsorbed water molecules and the
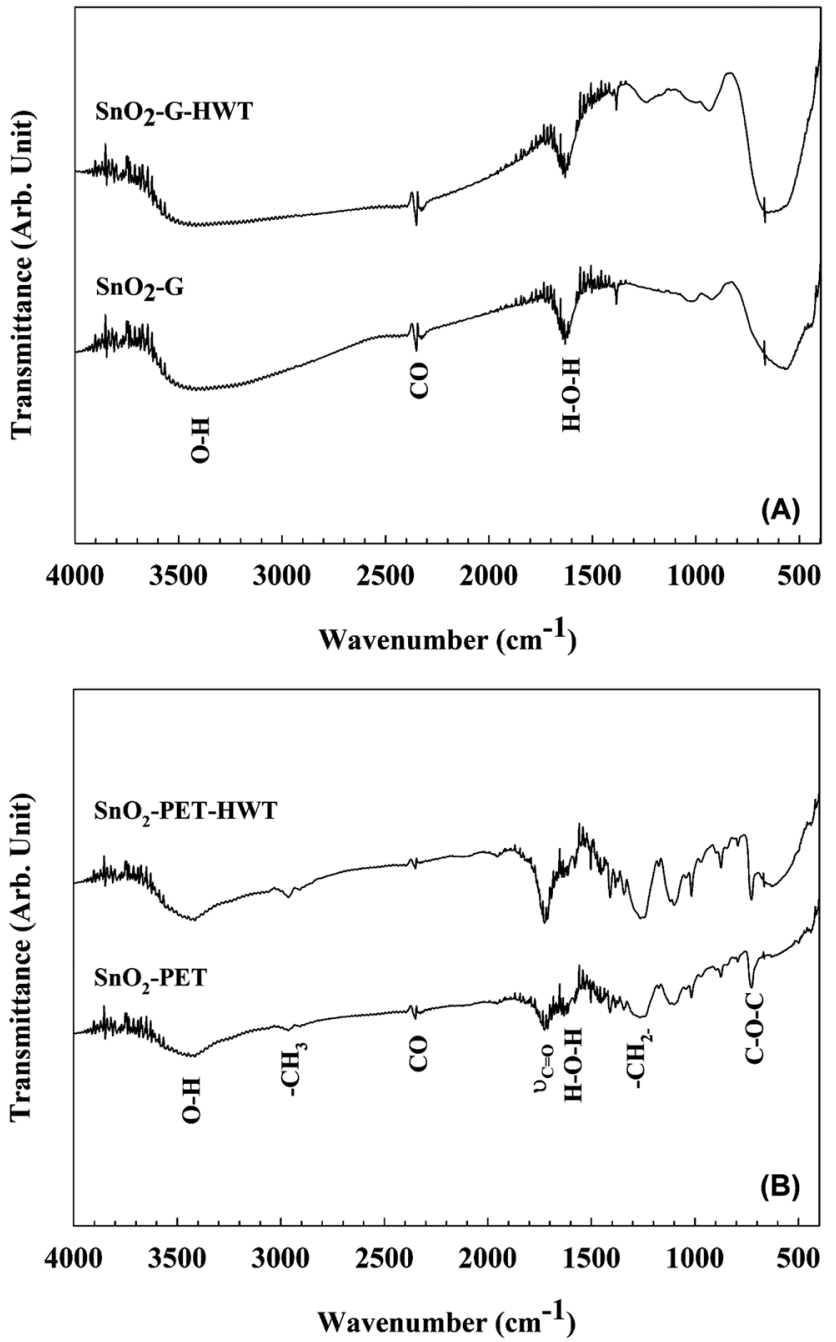

Fig. 4 The FT-IR spectra of $\mathrm{SnO}_{2}$. (A) $\mathrm{SnO}_{2}-\mathrm{G}$ before and after the HWT process, (B) $\mathrm{SnO}_{2}-$ PET before and after the HWT process. 
stretching vibrations of the hydroxyl groups ( $\mathrm{Sn}-\mathrm{OH}$, bridged bonding), respectively. ${ }^{21,22}$ It was found there was no significant change of these two bands corresponding to water content before and after HWT. This might result from the usage of $\mathrm{KBr}$ in the FTIR measurement since the adsorption behaviour of the water molecular on $\mathrm{KBr}$ would lead to the interference of IR transmittance measurement. ${ }^{23}$ Further examinations for defining the water content on the $\mathrm{SnO}_{2}$ surface were carried out and would be discussed in the next section. The broad band located between 500 and $800 \mathrm{~cm}^{-1}$ was attributed to the overlapping of the $\mathrm{Sn}-\mathrm{O}-\mathrm{Sn}, \mathrm{O}-\mathrm{Sn}-\mathrm{O}, \mathrm{Sn}-\mathrm{OH}$ bands or the symmetric and asymmetric stretching vibration bands of $\mathrm{SnO}_{2} \cdot{ }^{22,24-26}$ The increase of the band intensity was attributed to the transformation reaction from tin hydroxide to tin oxide and the bonding of the newly formed hydroxyl species with the crystallized $\mathrm{SnO}_{2}$ phase during HWT. ${ }^{27}$

The FTIR spectra of $\mathrm{SnO}_{2}-\mathrm{PET}$ before and after the HWT process are shown in Fig. 4(B). Similar to the $\mathrm{SnO}_{2}-\mathrm{G}$ samples, the peak at $1640 \mathrm{~cm}^{-1}$ and broad band in the range of 3100$3600 \mathrm{~cm}^{-1}$ indicated the presence of adsorbed water and the adsorbed hydroxide, and the further confirmations for the
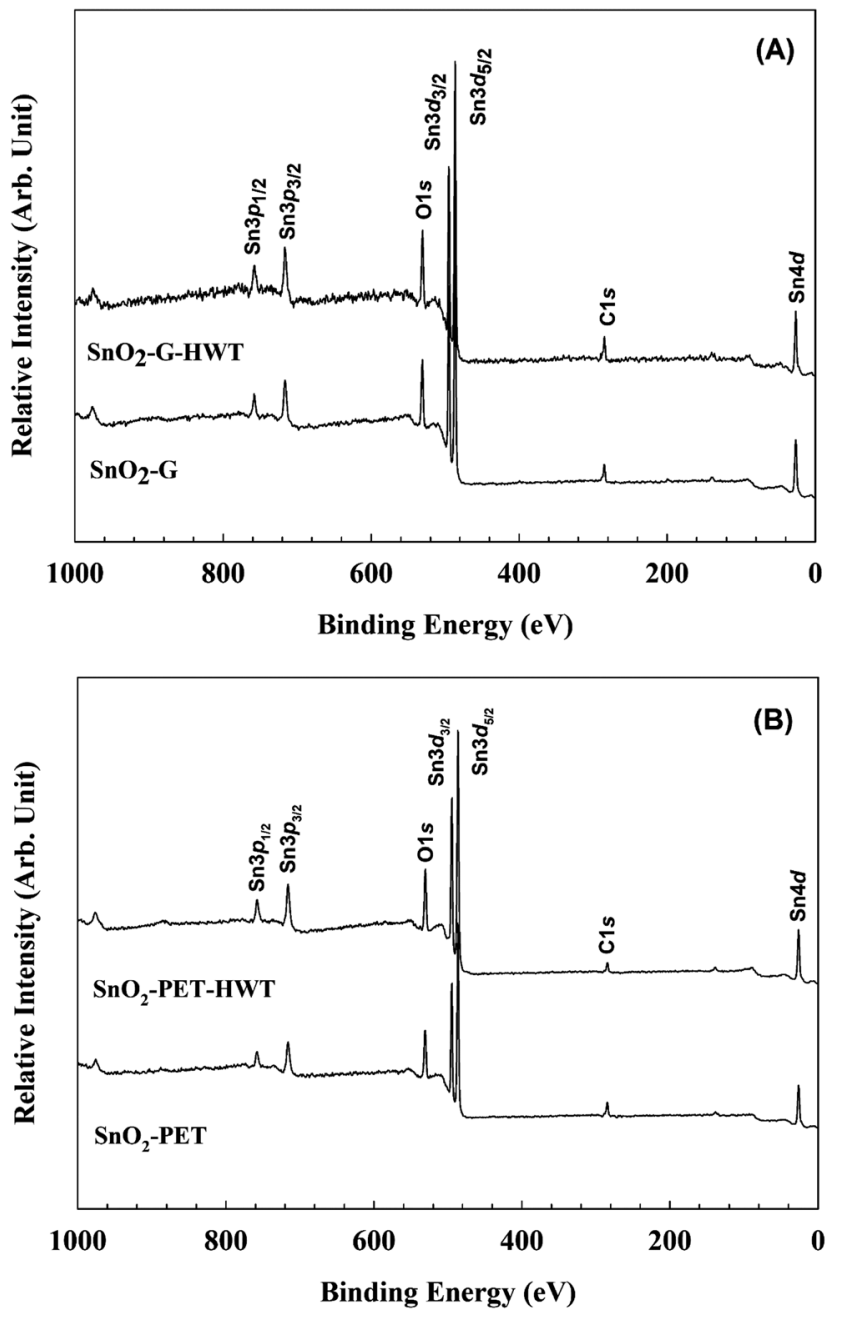

Fig. 5 The XPS survey spectrum of (A) $\mathrm{SnO}_{2}-\mathrm{G}$ and (B) $\mathrm{SnO}_{2}-\mathrm{PET}$. formation of the adsorbed hydroxide were carried out and would be discussed in the next section. The results of $\mathrm{SnO}_{2}-\mathrm{PET}$ and $\mathrm{SnO}_{2}-\mathrm{PET}-\mathrm{HWT}$ revealed several peaks corresponding to PET, including the ethers $(\mathrm{C}-\mathrm{O}-\mathrm{C})$ at $716 \mathrm{~cm}^{-1}$, methanediyl $\left(-\mathrm{CH}_{2}-\right)$ at $1250 \mathrm{~cm}^{-1}$, the stretching vibration band of the $\mathrm{C}=\mathrm{O}$ group at $1730 \mathrm{~cm}^{-1}$, and the methyl $\left(-\mathrm{CH}_{3}\right)$ at $2970 \mathrm{~cm}^{-1} \cdot{ }^{28,29}$ The broad band located within $400-700 \mathrm{~cm}^{-1}$ became stronger for the $\mathrm{SnO}_{2}$-PET samples underwent the HWT process. Similarly, this broad band was attributed to overlapping of the tin hydroxide species, Sn-O-Sn, and O-Sn-O peaks or the symmetric and asymmetric stretching vibration bands of $\mathrm{SnO}_{2}$. The increase of the band intensity might be induced by the formation of tin hydroxyl groups and $\mathrm{SnO}_{2}$ during the HWT process.

\subsection{The chemical state of $\mathrm{SnO}_{2}-\mathrm{G}$ and $\mathrm{SnO}_{2}-\mathrm{PET}$}

The chemical state of $\mathrm{SnO}_{2}-\mathrm{G}$ and $\mathrm{SnO}_{2}-$ PET samples with and without undergoing the HWT process were examined and evaluated by XPS, and the spectra are presented in Fig. 4 . All the XPS data were calibrated to the C1s peak at $284.6 \mathrm{eV}$ arising from the residual carbon on the sample surface. Besides, all the assigned peak positions for curve fitting were based on the Handbook of X-ray photoelectron spectroscopy. ${ }^{30}$ According to Fig. 5(A) and (B), the peaks corresponding to Sn4d, C1s, Sn3d, O1s, and $\mathrm{Sn} 3 \mathrm{p}$ were observed in the $\mathrm{SnO}_{2}-\mathrm{G}$ and $\mathrm{SnO}_{2}-\mathrm{PET}$ samples; in addition, impurities such as F, Na, and Si were not observed by the XPS survey spectrum. Fig. 6(A) and (B) demonstrate that the oxidation state of the $\mathrm{SnO}_{2}-\mathrm{G}$ and $\mathrm{SnO}_{2}-$ PET samples were mainly $\mathrm{Sn}^{4+}$ with a binding energy of approximately $486.6 \mathrm{eV}$. The O1s peak was composed of $\mathrm{O}-\mathrm{Sn}^{4+}$ and $-\mathrm{OH}$ bonding, corresponding to 530.9 and $532.0 \mathrm{eV}$, respectively. Both the $\mathrm{SnO}_{2}-\mathrm{G}$ and $\mathrm{SnO}_{2}-\mathrm{PET}$ samples were in the $\mathrm{O}-\mathrm{Sn}^{4+}$ state with tin hydroxide. Interestingly, the percentage of hydroxide concentration for both $\mathrm{SnO}_{2}-\mathrm{G}$ and $\mathrm{SnO}_{2}$-PET samples increased after the HWT process. We attributed this to the reaction of the surface of the $\mathrm{SnO}_{2}$ layer with dissociated water and the formation of a thin layer of hydroxyl derivatives $\left(\mathrm{Sn}(\mathrm{OH})_{x}\right)$ during the HWT process. Therefore, a considerable increase in the tin hydroxide signal was observed after HWT.

\subsection{Effects of the HWT process on $\mathrm{SnO}_{2}$}

Fig. 7 shows the surface morphology and cross-section characteristics of $\mathrm{SnO}_{2}-\mathrm{G}$ and $\mathrm{SnO}_{2}-$ PET prepared under the different process conditions (with or without the HWT process) under $30 \mathrm{k} \times$ magnification. The results revealed that both $\mathrm{SnO}_{2}-\mathrm{G}$ or $\mathrm{SnO}_{2}-\mathrm{PET}$ without HWT formed spherical nanoparticles. The particle size ranged from approximately 100 to $500 \mathrm{~nm}$. After the HWT process, both the morphology of $\mathrm{SnO}_{2}-\mathrm{G}$ and $\mathrm{SnO}_{2}-\mathrm{PET}$ revealed the same particle-like morphology. However, the surface after the HWT process was less uniform. The coalescence phenomenon between the $\mathrm{SnO}_{2}$ particles was found after HWT process. It could be attributed to the Ostwald ripening effect which led to the attachment of the crystallographically oriented tiny $\mathrm{SnO}_{2}$ particles and formed a larger one. According to Fig. $7(\mathrm{~A} 2)$ and (B2), the $\mathrm{SnO}_{2}-\mathrm{G}-\mathrm{HWT}$ exhibited a rough surface compared with that of the $\mathrm{SnO}_{2}-\mathrm{G}$ sample, and the 
$\begin{array}{lllllllllllll}536 & 534 & 532 & 530 & 528 & 526 & 492 & 490 & 488 & 486 & 484 & 482\end{array}$
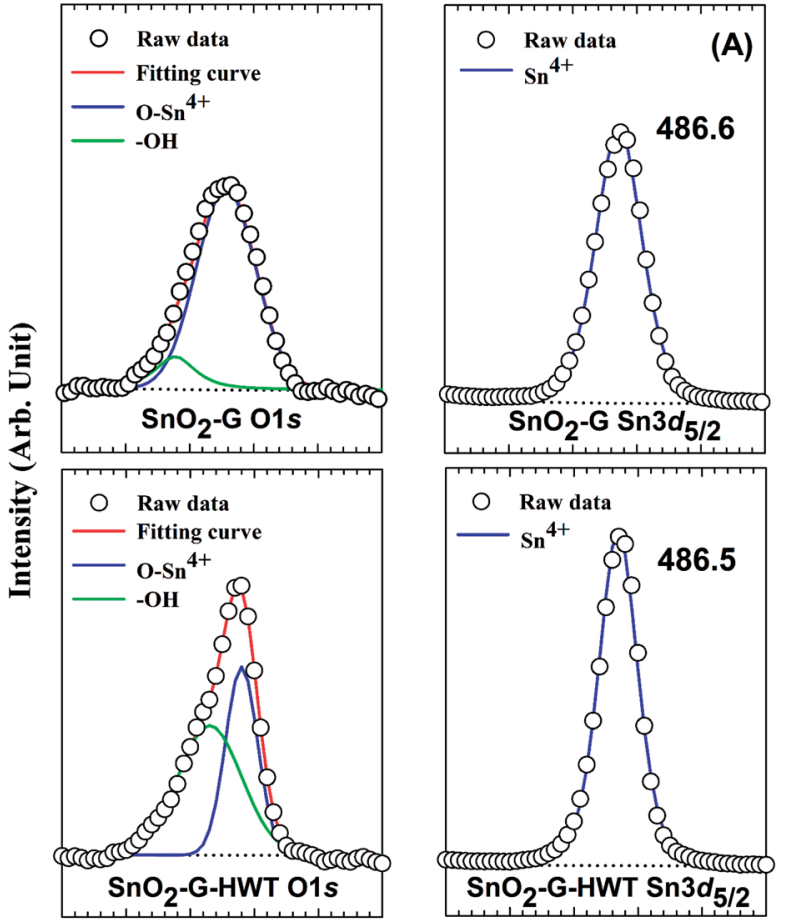

$\begin{array}{llllllllllll}536 & 534 & 532 & 530 & 528 & 526 & 492 & 490 & 488 & 486 & 484 & 482\end{array}$

Binding Energy (eV)
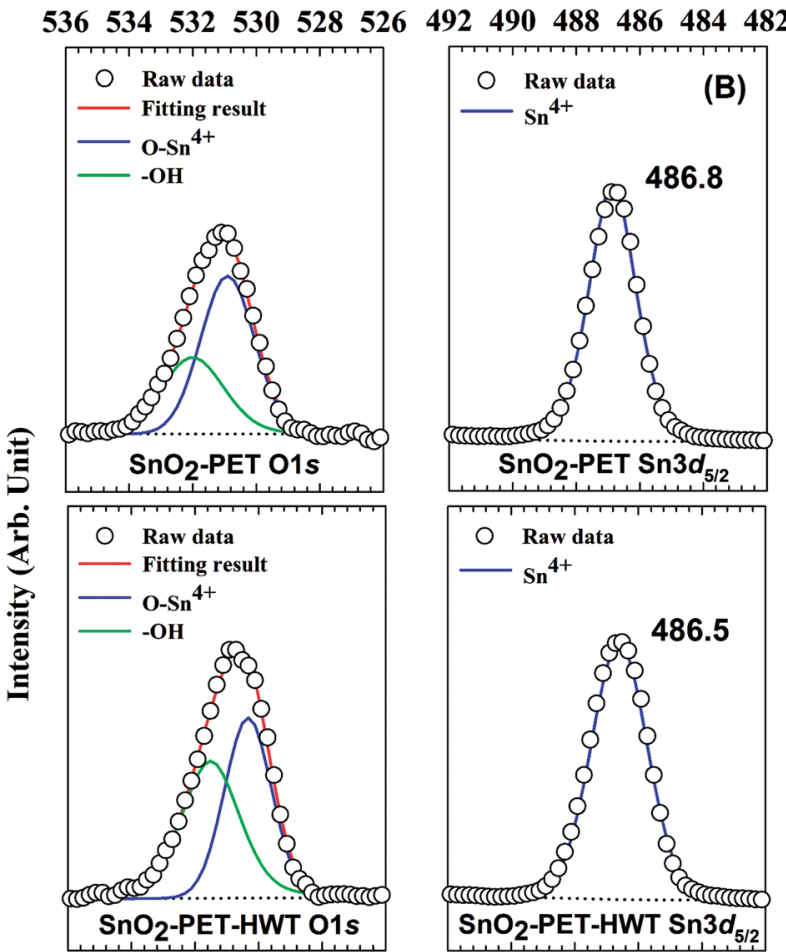

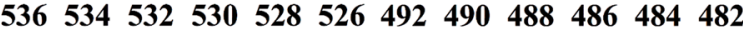

Binding Energy (eV)

Fig. 6 The XPS spectrum of $\mathrm{SnO}_{2}$ samples at binding energies of O1s and $\mathrm{Sn}_{3} \mathrm{~d}_{5 / 2}$ for $\mathrm{SnO}_{2}-\mathrm{G}$ and $\mathrm{SnO}_{2}-\mathrm{PET}$ samples before and after the HWT process. average thickness was approximately $400 \mathrm{~nm}$, which was thicker than the average $250 \mathrm{~nm}$ of the $\mathrm{SnO}_{2}-\mathrm{G}$ sample. The average thickness of the $\mathrm{SnO}_{2}$-PET-HWT was nearly the same as that of the $\mathrm{SnO}_{2}-\mathrm{G}-\mathrm{HWT}$ sample, and thicker than the $200 \mathrm{~nm}$ thickness of the as-prepared $\mathrm{SnO}_{2}-\mathrm{PET}$ film. The variation of the thickness and surface morphology were presumed to be induced by the transformation reaction from tin hydroxide to tin oxide, the new formation of tin hydroxide on the surface layer and the Ostwald ripening effect.

To realize the crystallinity and microstructure of $\mathrm{SnO}_{2}, \mathrm{XRD}$ measurements were performed and the results are shown in Fig. 8. The $\mathrm{SnO}_{2}-\mathrm{G}$ samples were amorphous before the HWT process, which coincided with the research reported by Uchiyama et al. ${ }^{31}$ According to the literature, amorphous tin oxide or hydroxide powders can be prepared at intermediate $\mathrm{pH}$ ranging from 4 to 7 using an $\mathrm{SnF}_{2}$ precursor solution. The $\mathrm{SnO}_{2}$ samples became crystallized cassiterite tin dioxide (JCPD \# 721147) after conducting the HWT process for $12 \mathrm{~h}$. The XRD pattern of $\mathrm{SnO}_{2}-\mathrm{G}$ comprised peaks at $26.5^{\circ}, 33.8^{\circ}, 38.9^{\circ}$, and $51.7^{\circ}$ associated with the ( $\left.h k l\right)$ planes (110), (101), (200), and (211), respectively. Similar XRD results were reported by Mikhaylov et al. ${ }^{32}$ In contrast, there was no clear difference in the XRD pattern of $\mathrm{SnO}_{2}$-PET before and after the HWT process. In other words, both the as-prepared $\mathrm{SnO}_{2}-\mathrm{PET}$ and $\mathrm{SnO}_{2}-\mathrm{PET}$ HWT samples were crystalline. The broad band within $20-30^{\circ}$

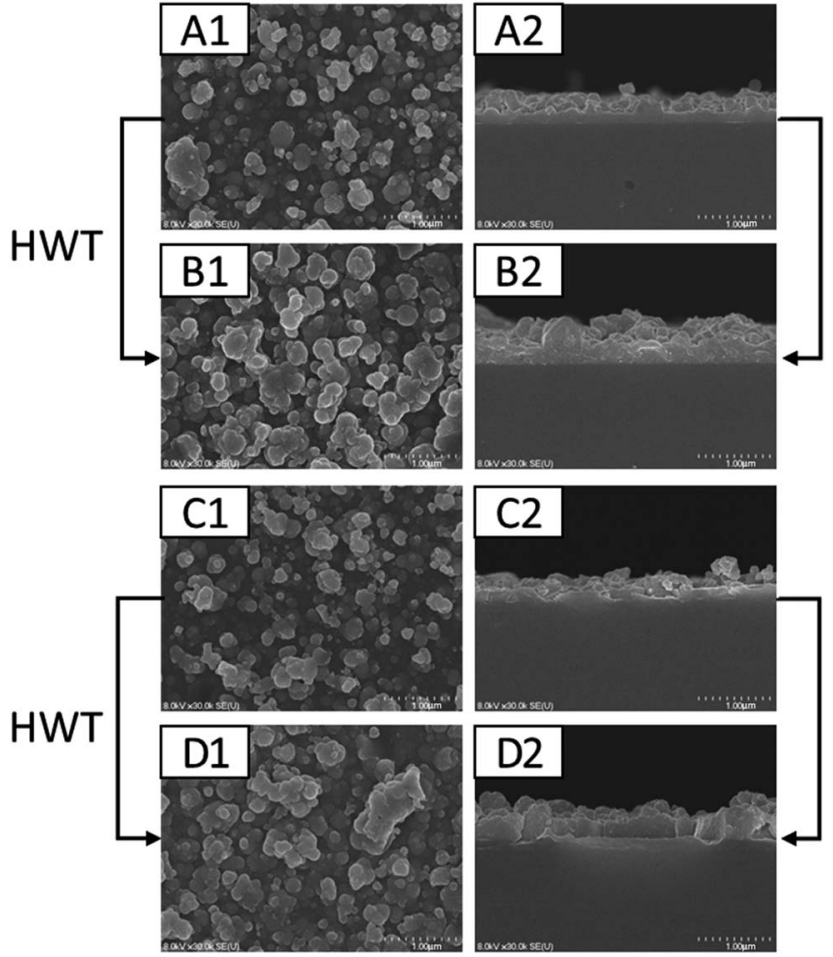

Fig. 7 The surface morphology and cross-section characteristics of $\mathrm{SnO}_{2}-\mathrm{G}$ and $\mathrm{SnO}_{2}-\mathrm{PET}$ samples. (A1), (B1), (C1), and (D1) show the surface morphology of $\mathrm{SnO}_{2}-\mathrm{G}, \mathrm{SnO}_{2}-\mathrm{G}-\mathrm{HWT}, \mathrm{SnO}_{2}-\mathrm{PET}$, and $\mathrm{SnO}_{2}-\mathrm{PET}-\mathrm{HWT}$, respectively. (A2) and (C2) are the cross-section images of $\mathrm{SnO}_{2}-\mathrm{G}$ and $\mathrm{SnO}_{2}-\mathrm{PET}$ before HWT, respectively. (B2) and (D2) show the cross-section of $\mathrm{SnO}_{2}-\mathrm{G}$ and $\mathrm{SnO}_{2}-\mathrm{PET}$ after HWT, respectively. 


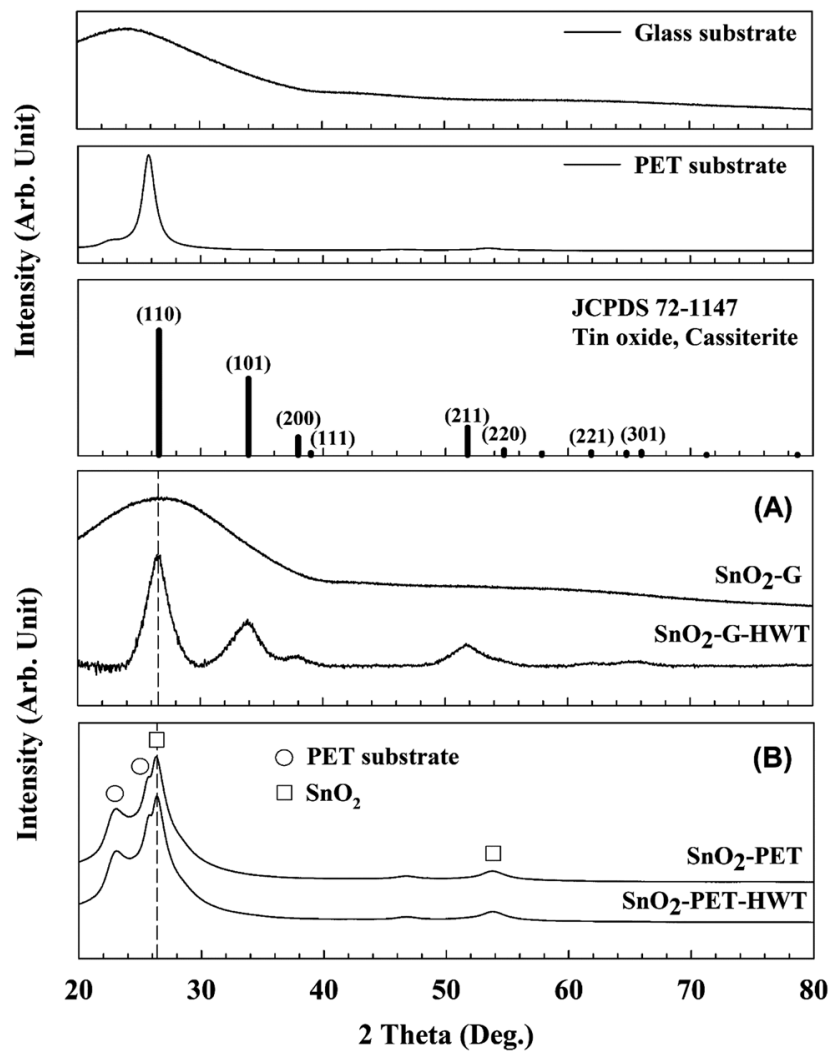

Fig. 8 The XRD patterns of $\mathrm{SnO}_{2}$ (JCPD 72-1147), the glass and PET substrate. (A) XRD patterns of the glass substrate and $\mathrm{SnO}_{2}-\mathrm{G}$ before and after the HWT process, (B) XRD patterns of the $\mathrm{SnO}_{2}-\mathrm{PET}$ before and after the HWT process.

was the overlapping peaks for PET and $\mathrm{SnO}_{2}$. The main peak at $26.5^{\circ}$ indicated the (110) orientation of $\mathrm{SnO}_{2}$, and the shoulder peaks located at $23.1^{\circ}$ and $25.7^{\circ}$ were attributed to the PET substrate. ${ }^{33}$ In contrast to $\mathrm{SnO}_{2}-\mathrm{G}$, there were only two growth orientations, (110) and (220), for the $\mathrm{SnO}_{2}-\mathrm{PET}$ sample, which were located at $26.5^{\circ}$ and $54.7^{\circ}$, respectively.

\subsection{Sensing properties of $\mathrm{SnO}_{2}-\mathrm{G}$ and $\mathrm{SnO}_{2}-\mathrm{PET}$}

The sensing properties of the $\mathrm{SnO}_{2}-\mathrm{G}-\mathrm{HWT}$ and $\mathrm{SnO}_{2}-\mathrm{PET}$ HWT are shown in Fig. 9. According to Fig. 9(A), the variation of the DC resistance of $\mathrm{SnO}_{2}-\mathrm{G}-\mathrm{HWT}$ and $\mathrm{SnO}_{2}-$ PET-HWT exhibited a downward trend with respect to the increase of $\%$ $\mathrm{RH}$ (5-95\%). There was no significant difference in the resistance of $\mathrm{SnO}_{2}-\mathrm{G}-\mathrm{HWT}$ and $\mathrm{SnO}_{2}-\mathrm{PET}-\mathrm{HWT}$ at low $\mathrm{RH} \%$; however, the discrepancy became larger at higher $\mathrm{RH} \%$. The resistance of $\mathrm{SnO}_{2}-\mathrm{G}-\mathrm{HWT}$ and $\mathrm{SnO}_{2}$-PET-HWT was 1.25 and 12.74 $\mathrm{M} \Omega$ at $95 \% \mathrm{RH}$, which was 35.2 and 3.5 times lower compared to the resistance of $\mathrm{SnO}_{2}-\mathrm{G}-\mathrm{HWT}$ and $\mathrm{SnO}_{2}-\mathrm{PET}$ HWT at 5\% RH, respectively. This considerable variation of resistance indicated that the water on the surface strongly influenced the condition of the film and led to a higher conductivity of $\mathrm{SnO}_{2}$. Compared with the $\mathrm{SnO}_{2}-\mathrm{G}-\mathrm{HWT}$ sample, the $\mathrm{SnO}_{2}$-PET-HWT sample exhibited the smaller change amount of resistance corresponding to the variation of $\mathrm{RH} \%$, which might be caused by the cracks inside the $\mathrm{SnO}_{2}$ layer owing to the unavoidable bending stress during the experiment, which would lead to the higher resistance and the worse electron transportation. Fig. 9(B) illustrates the sensitivity results of the $\mathrm{SnO}_{2}-\mathrm{G}-\mathrm{HWT}$ and $\mathrm{SnO}_{2}-\mathrm{PET}-\mathrm{HWT}$ samples with respect to different \% $\mathrm{RH}$ at room temperature. As expected, both the sensitivity of $\mathrm{SnO}_{2}-\mathrm{G}-\mathrm{HWT}$ and $\mathrm{SnO}_{2}-\mathrm{PET}-\mathrm{HWT}$ revealed a linear upward tendency corresponding to the increase of $\%$ RH. It is known $\mathrm{H}_{2} \mathrm{O}$ could absorb on the $\mathrm{SnO}_{2}$ surface in molecular or dissociative forms, ${ }^{34}$ and the water adsorption mechanism on ceramic oxide surfaces could be generalized by the formation of chemisorbed hydroxide layers followed by the physisorbed layers. ${ }^{35}$ According to the XPS results shown in Fig. 6, $\mathrm{SnO}_{2}$ and $\mathrm{Sn}-\mathrm{OH}$ groups with a chemical state of $\mathrm{Sn}^{4+}$ existed, and the signal intensity of $\mathrm{Sn}-\mathrm{OH}$ became stronger after samples underwent the HWT process. Herein, the HWT process performed in deionized water could be regarded as a $100 \% \mathrm{RH}$ environment at $100{ }^{\circ} \mathrm{C}$ (self-ionization constant of water at $\left.100^{\circ} \mathrm{C}, K_{\mathrm{w}}=55.0 \times 10^{-14}\right)$. During the process, the as-prepared $\mathrm{SnO}_{2}-\mathrm{G}$ layer would first crystallize, and the water molecular would chemisorb at the neck side of both the $\mathrm{SnO}_{2}-\mathrm{G}$ and $\mathrm{SnO}_{2}-\mathrm{PET}$ crystalline grains. Afterward, the lattice oxygen on the $\mathrm{SnO}_{2}$ surface was replaced and formed a $\mathrm{Sn}-\mathrm{OH}$ group layer,
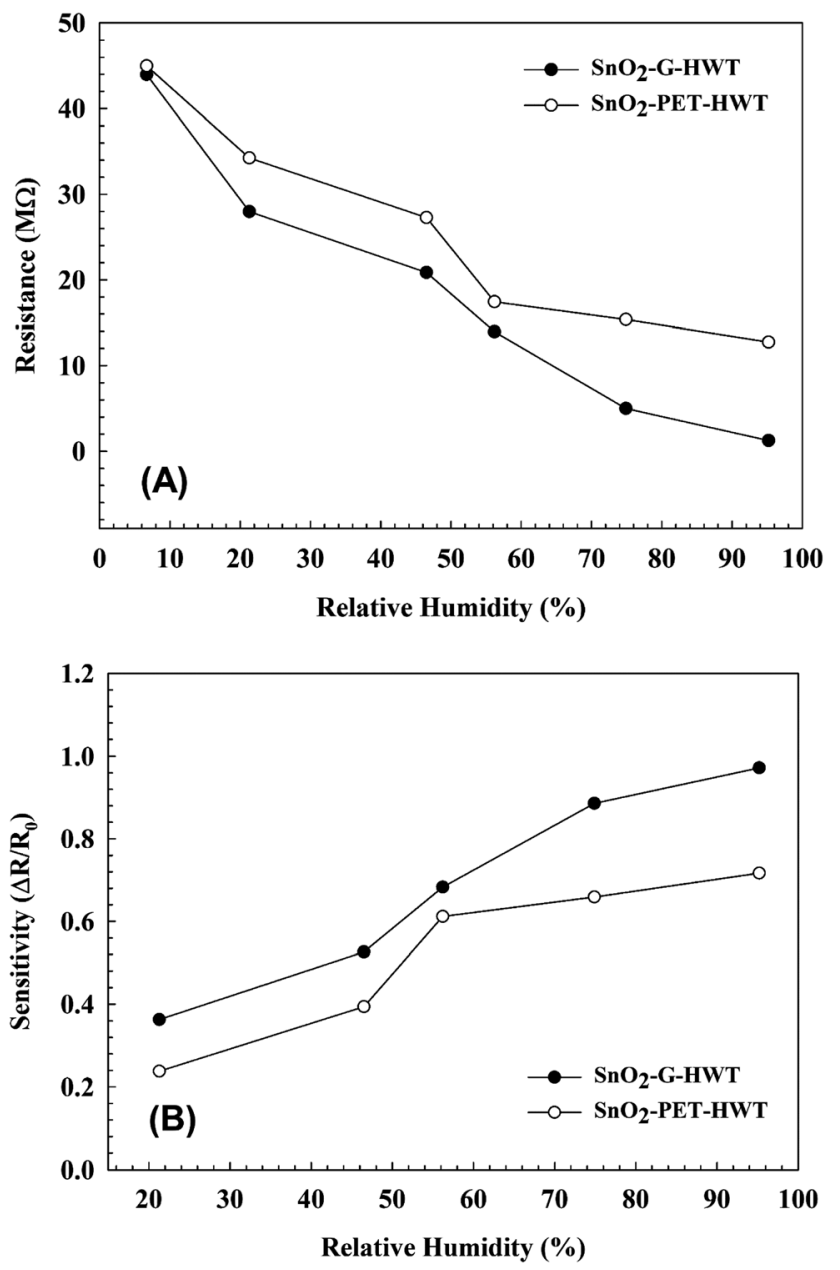

Fig. 9 Variation of the (A) DC resistivity and (B) sensitivity at different $\mathrm{RH} \%$ at the $20 \pm 1{ }^{\circ} \mathrm{C}$ of room temperature. 

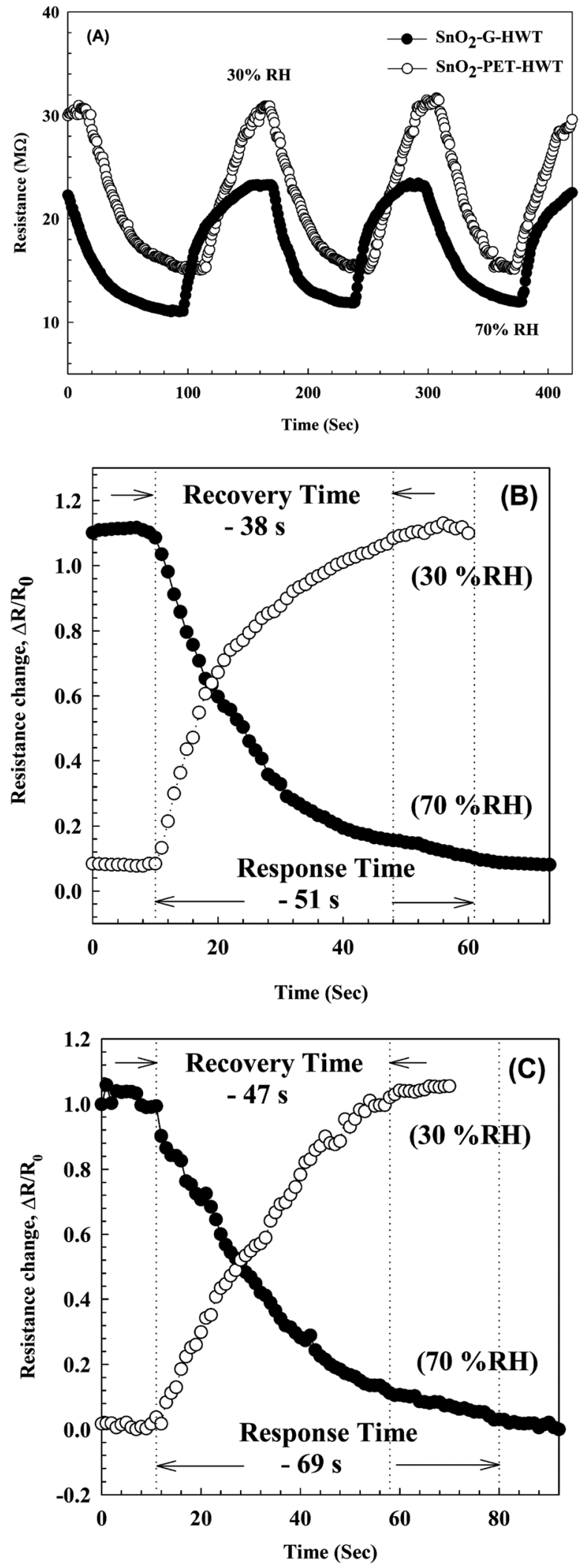

Fig. 10 (A) The resistance changes in the $\mathrm{SnO}_{2}-\mathrm{G}-\mathrm{HWT}$ and $\mathrm{SnO}_{2}-$ PET-HWT humidity sensor under three cycles of exposure to different $\% \mathrm{RH}$ values from $30 \%$ to $70 \%$ at $20 \pm 1{ }^{\circ} \mathrm{C}$. (B) and (C) showed the humidity response (humidification from 30 to $70 \% \mathrm{RH}$ ) and recovery (desiccation from 70 to $30 \% \mathrm{RH}$ ) curves of $\mathrm{SnO}_{2}-\mathrm{G}-\mathrm{HWT}$ and $\mathrm{SnO}_{2}-$ PET-HWT humidity sensor at $20 \pm 1{ }^{\circ} \mathrm{C}$, respectively. which is the dissociative water that would be physisorbed on the $\mathrm{SnO}_{2}$ film surface. The significant formation of tin hydroxyl groups possessing a high charge carrier density and strong electrostatic fields could provide mobile protons, singly bond with water molecules, and lead to the variation of the resistance. Because the HWT process was operated in water at $100{ }^{\circ} \mathrm{C}$, the formation of a physisorbed hydroxyl layer would still exist after the HWT process. Consequently, we believed that the movable $\mathrm{H}$ proton in hydrogenated $\mathrm{SnO}_{2}$ particle could act as the donor on the $\mathrm{SnO}_{2}$ layer surface and influence the surface chemical/ electrical conditions of the spin-spray/HWT $\mathrm{SnO}_{2}$ humidity sensor. Besides, this is the reason why the spin-spray/HWT $\mathrm{SnO}_{2}$ films could exhibit the room temperature humid sensing behaviour. To further confirm the reproducibility of the $\mathrm{SnO}_{2}$ films humidity sensor prepared in this study, the resistance changes in the $\mathrm{SnO}_{2}-\mathrm{G}-\mathrm{HWT}$ and $\mathrm{SnO}_{2}$-PET-HWT humidity sensor under periodically increasing and decreasing from 30 to $70 \%$ RH were conducted. According to Fig. 10(A), both the $\mathrm{SnO}_{2}-\mathrm{G}$ and $\mathrm{SnO}_{2}-\mathrm{PET}$ humidity sensors exhibited the similar humidity response within the humidity range between $30-70 \% \mathrm{RH}$. The similar characteristic in each cycle indicated the good reproducibility of the $\mathrm{SnO}_{2}$ layer humidity sensor prepared in this study. Fig. 10(B) and (C) exhibited the response and recovery behaviour of the $\mathrm{SnO}_{2}-\mathrm{G}-\mathrm{HWT}$ and $\mathrm{SnO}_{2}$-PETHWT humidity sensor. The $R_{0}$ and $\Delta R$ in response/recovery comparison plot indicated the minimum resistance measured in the first cycle under $70 \% \mathrm{RH}$ and the change of the resistance from $R_{0}$ to the measured resistance after the sample exposed to $\mathrm{RH}$ value ranging from 30 to $70 \% \mathrm{RH}$. The response/recovery time of the $\mathrm{SnO}_{2}-\mathrm{G}-\mathrm{HWT}$ and $\mathrm{SnO}_{2}$-PET-HWT humidity sensor were 51/38 s and 69/47 s respectively for one cycle (\% RH values from 30 to $70 \%$ ) of adsorption and desorption. It was found that both the response and recovery time of the $\mathrm{SnO}_{2}-\mathrm{G}-$ HWT sample were faster than that of the $\mathrm{SnO}_{2}-\mathrm{PET}$-HWT samples. It should be noted that the thickness of $\mathrm{SnO}_{2}-\mathrm{G}-$ HWT was nearly same as $\mathrm{SnO}_{2}$-PET-HWT samples, and the experimental conditions such as the temperature and measurement system were same. Therefore, the difference of response and recovery time should result from the reaction surface area. According to the SEM results showed in Fig. 7(B1) and (D1), the $\mathrm{SnO}_{2}-\mathrm{G}-\mathrm{HWT}$ sample revealed a rougher surface compared with the $\mathrm{SnO}_{2}$-PET-HWT samples. We believe that the rougher surface of $\mathrm{SnO}_{2}-\mathrm{G}-\mathrm{HWT}$ samples could provide larger reaction surface area. Thus, $\mathrm{SnO}_{2}-\mathrm{G}-\mathrm{HWT}$ layer humidity sensor could possess a faster response and recovery time. A

Table 1 Comparison of sensing properties of $\mathrm{SnO}_{2}$-based room temperature humidity sensors reported in literature

\begin{tabular}{llll}
\hline & $\begin{array}{l}\text { Measurement } \\
\text { Mange }(\% \mathrm{RH})\end{array}$ & Sensitivity & Reference \\
\hline $\mathrm{SnO}_{2}-\mathrm{G}-\mathrm{HWT}$ & $5-95$ & $0.36-0.97[\Delta R / R]$ & This work \\
$\mathrm{SnO}_{2}-\mathrm{PET}-\mathrm{HWT}$ & & $0.24-0.72[\Delta R / R]$ & \\
$\mathrm{Fe}-\mathrm{SnO}_{2}$ & $0-100$ & $0.8[\Delta R / R]$ & 4 \\
$\mathrm{SFPG}$ & $0-100$ & $3.23[\Delta R / R]$ & \\
$\mathrm{SnO}_{2}-\mathrm{RGO}$ & $11-97$ & $0.15-0.45[\Delta R / R]$ & 36 \\
$\mathrm{SnO}_{2}$ & $5-95$ & $0-0.98[\Delta R / R]$ & 37
\end{tabular}


comparison of the sensitivity of other humidity sensors at room temperature reported in the literature is shown in Table 1. According to Table 1, the $\mathrm{SnO}_{2}$-based humidity sensor prepared in this research showed equivalent sensing properties to other sensors reported in the literature. However, the $\mathrm{SnO}_{2}$-based sensor in this study was the only one that was prepared at a temperature below $100{ }^{\circ} \mathrm{C}$.

\section{Conclusions}

In this research, transparent and crystalline $\mathrm{SnO}_{2}$ films were fabricated on non-seeded glass and directly deposited on a flexible PET substrate at a temperature below $100{ }^{\circ} \mathrm{C}$. The HWT process did not only trigger the crystallization reaction of $\mathrm{SnO}_{2}$ but simultaneously induce the formation of hydroxyl species on the $\mathrm{SnO}_{2}$ surface, which led to an improvement of the conductivity of the as-prepared $\mathrm{SnO}_{2}$ films on both glass and PET substrates. The reaction mechanism of the HWT process was mainly based on the concept of typical water chemisorption and physisorption for ceramic type semiconductor sensing materials. Both the $\mathrm{SnO}_{2}-\mathrm{G}$ and $\mathrm{SnO}_{2}-\mathrm{PET}$ exhibited a dominant growth orientation along (110) according to the XRD results, which could form the stable configuration with dissociated water. The humidity sensing properties of both $\mathrm{SnO}_{2}-\mathrm{G}$ and $\mathrm{SnO}_{2}$-PET after the HWT process revealed an uptrend corresponding to the increase of the relative humidity, and the response/recovery time of $\mathrm{SnO}_{2}-\mathrm{G}-\mathrm{HWT}$ and $\mathrm{SnO}_{2}-\mathrm{PET}-\mathrm{HWT}$ exhibited $51 / 38 \mathrm{~s}$ and $69 / 47 \mathrm{~s}$ in the $\% \mathrm{RH}$ range of $30-70 \%$ at $20 \pm 1{ }^{\circ} \mathrm{C}$ of room temperature, respectively. The simple, lowtemperature, and low-cost synthesis method of $\mathrm{SnO}_{2}$ reported in this study shows a good prospect for $\mathrm{SnO}_{2}$-based wearable electronic devices.

\section{Conflicts of interest}

There are no conflicts to declare.

\section{Acknowledgements}

This work was supported by a Grant-in-Aid for Scientific Research (B), 15H04122, of The Ministry of Education, Culture, Sports, Science and Technology (MEXT). A part of this work was also supported by Research Grant, The Murata Science Foundation. We thank Zoran Dinev, PhD, from Edanz Group (www.edanzediting.com/ac) for editing a draft of this manuscript.

\section{References}

1 Z. M. Jarzebski and J. P. Marton, J. Electrochem. Soc., 1976, 123, 299c.

2 A. Azam, S. S. Habib, N. A. Salah and F. Ahmed, Int. J. Nanomed., 2013, 8, 3875.

3 X. X. Lian, Y. Li, X. Q. Tong, Y. L. Zou, X. L. Liu, D. M. An and Q. Wang, Appl. Surf. Sci., 2017, 407, 447.
4 D. Toloman, A. Popa, M. Stan, C. Socaci, A. R. Biris, G. Katona, F. Tudorache, I. Petrila and F. Iacomi, Appl. Surf. Sci., 2017, 402, 410.

5 X. L. Xu, Y. Chen, G. H. Zhang, S. H. Yan, H. Q. Bian, Q. Chen, Y. Lu and S. Y. Ma, Mater. Lett., 2017, 195, 159.

6 S. Nasresfahani, M. H. Sheikhi, M. Tohidi and A. Zarifkar, Mater. Res. Bull., 2017, 89, 161.

7 X. Z. Wang, S. Qiu, J. R. Liu, C. Z. He, G. X. Lu and W. Liu, Eur. J. Inorg. Chem., 2014, 5, 863.

8 S. H. Mohamed, J. Alloys Compd., 2011, 510, 119.

9 S. Das and V. Jayaraman, Prog. Mater. Sci., 2014, 66, 112.

10 L. Vayssieres and M. Graetzel, Angew. Chem., Int. Ed., 2004, 43, 3666.

11 Y. C. Her, J. Y. Wu, Y. R. Lin and S. Y. Tsai, Appl. Phys. Lett., 2006, 89, 89.

12 A. K. Subramani, N. Matsushita, T. Watanabe, M. Tada, M. Abe, K. Kondo and M. Yoshimura, Mater. Sci. Eng., B, 2008, 148, 136.

13 H. Wagata, N. Ohashi, T. Taniguchi, A. K. Subramani, K. I. Katsumata, K. Okada and N. Matsushita, Cryst. Growth Des., 2010, 10, 3502.

14 A. Lamberti, A. Chiodoni, N. Shahzad, S. Bianco, M. Quaglio and C. F. Pirri, Sci. Rep., 2015, 5, 7808.

15 N. S. Saadi, L. B. Hassan and T. Karabacak, Sci. Rep., 2017, 7, 7158.

16 K. Nose, A. Y. Suzuki, N. Oda, M. Kamiko and Y. Mitsuda, Appl. Phys. Lett., 2014, 104, 091905.

17 V. Tomer and S. Duhan, Sens. Actuators, B, 2015, 220, 192.

18 L. Greenspan, J. Res. Natl. Bur. Stand., Sect. A, 1977, 81A, 89.

19 H. Cankurtaran, O. Yazici, S. Dinc and F. Karaman, Int. J. Electrochem. Sci., 2013, 8, 3265.

20 D. S. Madge, Entomol. Exp. Appl., 1961, 4, 143.

21 D. Amalric-Popescu and F. Bozon-Verduraz, Catal. Today, 2001, 70, 139.

22 J. A. Bonacin, R. R. Passos and L. A. Pocrifka, Mater. Res., 2015, 18, 639.

23 S. H. Gordon, R. E. Harry-O'kuru and A. A. Mohamed, Talanta, 2017, 174, 587.

24 H. Zhang, Y. Liu, K. Zhu, G. Siu, Y. Xiong and C. Xiong, J. Phys.: Condens. Matter, 1999, 10, 11121.

25 P. Harrison and A. Guest, J. Chem. Soc., Faraday Trans., 1987, 83, 3383.

26 R. Hu, J. Zhao and J. Zheng, Mater. Lett., 2017, 197, 59.

27 B. Skariah, J. Naduvath and B. Thomas, Ceram. Int., 2015, 42, 7490.

28 Z. Huang, L. Bi, Z. Zhang and Y. Han, Mol. Med. Rep., 2012, 6, 709.

29 Y. Zhao, X. Song, Q. Song and Z. Yin, CrystEngComm, 2012, 14, 6710.

30 J. Moulder, W. Stickle, P. Sobol and K. Bomben, Handbook of $X$-Ray Photoelectron Spectroscopy, Physical Electronics USA inc., Minnesota, 1995, 126.

31 H. Uchiyama, H. Ohgi and H. Imai, Cryst. Growth Des., 2006, 6, 2186.

32 A. Mikhaylov, A. Medvedev, T. Tripol'skaya, V. Popov, A. Mokrushin, D. Krut'ko, P. Prikhodchenko and O. Lev, Dalton Trans., 2017, 46, 16171. 
33 S. Y. Tsai, Y. M. Lu, J. J. Lu and M. H. Hon, Surf. Coat. Technol., 2006, 200, 3241.

34 Z. Chen and C. Lu, Sens. Lett., 2005, 3, 274.

35 H. Farahani, R. Wagiran and M. Hamidon, Sensors, 2014, 14, 7881.
36 D. Zhang, H. Chang and R. Liu, J. Electron. Mater., 2016, 45, 4275.

37 M. Parthibavarman, V. Hariharan and C. Sekar, Mater. Sci. Eng., C, 2011, 31, 840. 